\title{
Potential of Protein-based Anti-metastatic Therapy with Serpins and Inter $\alpha$-Trypsin Inhibitors
}

\author{
ULRICH H. WEIDLE ${ }^{1}$, FABIAN BIRZELE ${ }^{2}$ and GEORG TIEFENTHALER ${ }^{3}$ \\ ${ }^{1}$ Roche Pharma Research and Early Development, Roche Innovation Center Munich, Penzberg, Germany; \\ ${ }^{2}$ Roche Pharma Research and Early Development, Pharmaceutical Sciences, Basel, Switzerland; \\ ${ }^{3}$ Roche Pharma Research and Early Development, Large Molecule Research, \\ Roche Innovation Center Munich, Penzberg, Germany
}

\begin{abstract}
In this review we summarize the principles of anti-metastatic therapy with selected serpin family proteins, such as pigment epithelial-derived factor (PEDF) and maspin, as well as inter a-trypsin inhibitor (IaIs) light chains (bikunin) and heavy chains (ITIHs). Case-by-case, antimetastatic activity may be dependent or independent of the protease-inhibitory activity of the corresponding proteins. We discuss the incidence of target deregulation in different tumor entities, mechanisms of deregulation, contextdependent functional issues as well as in vitro and in vivo target validation studies with transfected tumor cells or recombinant protein as anti-metastatic agents. Finally, we comment on possible clinical evaluation of these proteins in adjuvant therapy.
\end{abstract}

The vast majority of cancer deaths are due to metastatic disease (1). The sum of all individual steps resulting in tumor metastases is referred to as the metastatic cascade (2-5). Metastasis fomation is a highly inefficient process which starts with increased tumor invasiveness due to epithelial mesenchymal transition (EMT) in the tumor periphery, degradation of the extracellular matrix (ECM), and intravasation and dissemination of individual tumor cells or tumor cell clusters. In the circulation, these tumor cells are protected by platelets and neutrophils and eventually arrive

This article is freely accessible online.

Correspondence to: Georg Tiefenthaler, Roche Innovation Center Munich, 82377 Penzberg, Germany. Tel: +49 8856602343, e-mail: georg.tiefenthaler@roche.com

Key Words: Adjuvant anti-metastatic therapy, bikunin, inter $\alpha$-trypsin inhibitors, in vitro and in vivo target validation, maspin, pigmentepithelial derived factor, protein substitution therapy, review. at secondary sites prior to transendothelial migration. The microenvironment in the new organ parenchyma is poorly adapted to colonization with the consequence that tumor cells enter a dormant state which may range from days to several years $(6,7)$. This state is referred to as minimal residual disease (MRD). In addition, the metastatic microenvironment can be adapted in favour of tumor colonization by bonemarrow-derived cells, resulting in the formation of a prometastatic niche $(8,9)$. It is believed that only tumor cells with the propensity for tumor initiation, corresponding to a cancer stem cell (CSC) state, are able to act as founders of metastatic colonies (10). Factors influencing metastatic outgrowth are the immune status of the patient, blood supply, composition of the ECM and recruitment of a compatible stromal microenvironment. The metastatic process may begin early or late in primary tumor formation and may require a brief period or decades to complete $(11,12)$. Multi-organ colonization or tissue-specific colonization are determined by genetic programmes (13). Altogether, the identification and validation of targets suitable for intervention with metastatic disease should be viewed as a high-priority approach in oncology. In this review article we focus on the role of protease-related proteins as potential agents for prevention and treatment of metastatic disease.

\section{Serpins - General Comments}

In humans, serine protease inhibitors (serpins) consist of a gene family of 36 protein-encoding genes and five pseudogenes (14). Most serpins inhibit serine proteases e.g. of the chymotrypsin family, a minority inhibits cysteine proteases such as caspases and cathepsins $(17,18)$. In addition, functions independent of protease inhibition were noted $(15,16)$. Serpins in general are secreted molecules, but a class of intracellular serpins has also been identified (19). The protease-inhibitory function of serpins is involved in 
diverse physiological and pathophysiological processes such as inflammation, coagulation, dementia, tumorigenesis and metastasis (20). On the other hand, serpins functioning as chaperones or being involved in hormone storage and transport are independent of protease inhibition $(15,16)$. Serpins are composed of 330 to 500 amino acids and their metastable structure is mediated by a highly conserved secondary structure composed of three $\beta$-sheets, nine $\alpha$ helices and a reactive center loop (RCL) which acts as a bait for proteases (21). The RCL forms an extended, exposed structure above the body of the serpin scaffold, and its cleavage and subsequent insertion into target proteases is crucial for effective protease inhibition $(22,23)$. In the final serpin-protease complex the enzyme is frozen at the acylintermediate step of the catalytic cycle and the protease structure is severely distorted in comparison to its native conformation $(22,23)$. Thus, the enzyme is inhibited irreversibly due to a conformational change which disrupts the active site. This type of mode of action (MOA) is in contrast to competitive inhibition by protease inhibitors that bind to and block access to the active site of the respective protease. Serpins are vulnerable to mutations, protein misfolding, formation of inactive polymers, and can induce organ failure due to accumulation of polymers (14-16).

\section{Metastasis-promoting Serpins}

In this review, we focus on the metastasis-inhibitory roles of serpins, however, a brain metastasis-promoting function of serpins in lung- and breast cancer has also been described (24). Cells derived from brain metastases of these tumor types typically express high levels of neuroserpin (NS) and serpin $\mathrm{B} 2$, presumably to prevent generation of plasmin which is lethal to tumor cells invading the brain parenchyma (24). Plasmin, which is generated from plasminogen by plasminogen activators urokinase plasminogen activator (uPA) and tissuetype plasminogen activator (tPA) $(25,26)$ can mobilize soluble FasL from FasL-expressing astrocytes and thus induce tumor cell death by activating Fas signaling in tumor cells (27). Another substrate of plasmin is L1 cancer cell adhesion molecule (L1CAM) (28-30) which promotes spreading of tumor cells on the abluminal surface of capillaries and their metastatic outgrowth. In lung adenocarcinoma, expression of NS and serpin B2 is associated with brain metastasis both as individual genes or in combination (24). In line with these findings are observations that serpin levels in several types of tumors and blood are associated with poor outcome in several types of cancer (31-33).

\section{Pigment Epithelium-derived Factor (PEDF)}

PEDF is a $50-\mathrm{kD}$ glycoprotein, and a non-protease-inhibitory member of the serpin family (34-37). It was discovered as a factor promoting the differentiation of retinal progenitor cells into cells exhibiting a neuronal phenotype and as a promoter of differentiation of retinoblastoma cells (38). PEDF is involved in diverse biological processes such as neurogenesis, neuroprotection, retina protection, inflammation, stem cell renewal, anti-angiogenesis and inhibition of metastasis (3437). Various functional domains mediating anti-angiogenesis, neurotrophy, cell differentiation, apoptosis, collagen- lamininand heparin binding as well as multiple phosphorylation sites have been identified $(34,35)$. In addition, several PEDF receptors, such as PEDF-R, PLXDC1 and PLXDC2 have been described $(34,39)$. The physiological consequences of PEDF/PEDFRs interaction are context-dependent, with respect to cell type and expression pattern of the corresponding receptor types. Therefore, PEDF/PEDFRs interaction represents a complex system of signaling in relation to physiological functions and also with respect to metastasis.

PEDF has been identified as a suppressor of metastasis with impact on invasion, migration, proliferation, apoptosis and angiogenesis (34-38) by targeting tumor cells as well as endothelial cells. The invasion-promoting functions of matrix metallo-proteinases (MMPs) and their inhibition by PEDF are supported by several observations. For example, in chondrosarcoma cells, PEDF blocks trafficking of membranetethered MT1-MMP to the cell surface $(39,40)$. Also, downregulation of MT1-MMP by PEDF has been described (41). PEDF can be cleaved by MMP2 and MMP9 and it blocks extravasation of tumor cells (42). Anti-invasion properties of PEDF can also be mediated by mitogen activated protein kinase (MAPK) p38 which together with mitogen activated protein kinase kinases 3 and 6 (MKK3 and MKK6) is activated by interaction of PEDF with a not yet identified receptor (42). Another important function of PEDF is its ability to promote apoptosis of endothelial and tumor cells. PEDF-mediated induction of apoptosis is consistently associated with increased levels of $\mathrm{p} 53$ and Bcl-2 associated $\mathrm{X}$ protein (Bax), and inhibition of Bcl2 has been observed in prostate- (43), glioma (44), pancreatic (45), osteosarcoma (46) and Wilms tumorderived cancer cells (47). Furthermore, PEDF is lost during progression of melanoma (48). Pro-apoptotic effects of PEDF can be mediated by cluster of differentation 95/95L (CD95/CD95L) interaction (49), inhibition of FLICE-inhibitory protein (FLIP) (50) or phosphorylation of vascular endothelial growth factor receptor 1 (VEGFR1) by VEGF (51) in tumor and endothelial cells. PEDF induces CD95L, and CD95Lmediated apoptosis relies on $\mathrm{p} 38$, mitogen-activated protein kinase 5 (MEK5), and extracellular signal-regulated kinase 5 (ERK5)-mediated induction of peroxisome proliferatioractivated receptor $\gamma$ (PPAR $\gamma$ ) which promotes expression of CD95L. The latter can induce apoptosis of endothelial cells and tumor cells by interaction with CD95 $(49,52)$. Furthermore, PEDF triggers jun N-terminal protein kinase (JNK)-mediated 
phosphorylation of nuclear factor of activated T-cells (NFATc2), sequestering it in the cytoplasm and thus preventing NFATc2-mediated expression of apoptosis-inhibitor FLIP, an inhibitor of the cell-death mediator caspase 8 (53). The antiangiogenic effect of PEDF largely seems to be mediated by modulation of the VEGF pathway (54). The MOA of PEDF is summarized in Figure 1.

In several in vivo models the anti-metastatic function of PEDF either with PEDF-transfected cells, recombinant PEDF or PEDF-derived peptides was demonstrated as outlined below. So, PEDF-transfected 4T1 murine breast cancer cells as well as similarly transfected human MDA-MB- 231-BR breast cancer cells displayed significantly reduced outgrowth of experimental brain metastasis after tail vein injection and intracranial implantation (55). The role of PEDF in metastasis formation was also investigated in a murine model of ocular melanoma. Forty percent of primary uveal melanomas metastasize to the liver (56). In vitro, B16LS9 melanoma cells treated with PEDF lost the ability to migrate and form tubes, and in vivo, tumor growth, number of lymphatic micrometastases and tumor microvessel density were decreased in mice injected with PEDF-overexpressing B16LS9 melanoma cells (56). In addition, a xenograft model of Wilms tumor, a pediatric kidney cancer, was shown to be PEDF-responsive. Thus, intraperitoneal injection of recombinant PEDF inhibited the growth of PK-NEP-1 human Wilms tumor cells by $60 \%$, and no evidence of lung metastases was found in these mice (47). Also, microvessel density and mitotic index of tumor cells were reduced in the treated animals. Finally, osteosarcoma is another PEDFsensitive tumor in preclinical models (57). Osteosarcoma is a pediatric tumor with the propensity to metastasize to the lungs. Recombinant PEDF inhibited cell proliferation and induced apoptosis in rat UMR 106-01 and human SaOS-2 osteosarcoma cell lines in vitro (57). Dose-dependent inhibition of cellular invasion through matrigel, increased adhesion to collagen type I as well as reduced VEGF secretion induced by PEDF was observed in both cell lines (57). Coadministration of PEDF during inoculation with Saos- 2 cells reduced primary tumor size by $40 \%$ and the number and size of lung metastases by $70 \%$ after orthotopic implantation into the bones in mice. Here, recombinant PEDF was only effective as an inhibitor in the orthotopic, but not in ectopic, i.e. subcutaneous, setting, suggesting an interaction between PEDF and the tumor microenvironment in bone. Similarly, PEDF-derived peptides were evaluated in the Saos-2-based orthotopic osteosarcoma model by continuous administration through osmotic micro pumps (58). Peptide StVOrth2 (residues 78-102) inhibited tumor growth by $50 \%$, whereas peptide StVOrth3 (residues 90-114) reduced the number and mass of pulmonary nodules by $80 \%$ (58). For PEDF-based drug development, the identification of biomarkers indicative for PEDF-mediated metastasis-inhibitory signaling is an essential requirement for identification of PEDF-responsive tumors. Thus, it remains to be shown if in addition to the outlined pediatric tumors other tumor entities are candidates for PEDF-related treatment of metastasis.

\section{Maspin}

The mRNA of maspin (serpin B5) was found to be downregulated in mammary carcinoma cell lines in comparison to non-transformed mammary epithelial cells by differential hybridization (59). In addition, maspin is down-regulated in prostate- and gastric cancer and melanoma, but was found to be overexpressed in pancreatic, colorectal and thyroid cancer in comparison to corresponding non-transformed tissues (60). Accordingly, the expression levels and functions of maspin appear to be strongly context-dependent (61-63). Here we discuss the anti-metastatic functions of maspin. In addition to the differential regulation of its expression, another remarkable feature of maspin is its distribution to different cellular locations with possible compartment-specific functions (60-64). Therefore, maspin can be secreted and associated with the plasma membrane and endocytic vesicles in the cytoplasm, but also nuclear localization has been reported. A further remarkable feature of maspin is the regulation of its expression by epigenetic modification of its gene contributing to contextdependent modulation of its activity (64). Cytoplasmic maspin potentially interacts with and thus modulates components of several distinct pathways while pericellularly located maspin might be responsible for paracrine interaction with the tumor microenvironment. Finally, nuclear maspin has been shown to interact with chromatin and regulate transcriptional programmes $(65,66)$ (Figure 2).

A property of maspin which affects tumor growth as well as metastasis formation is its ability to inhibit angiogenesis (67). Maspin directly acts on endothelial cells by inhibition of fibroblast-growth factor- and VEGF-induced migration and attenuation of their capability to induce mitogenesis and tube formation in vitro. In vivo, maspin was found to block neovascularization in the rat cornea pocket model and to inhibit growth of xenograft tumors with a concomittant decrease of microvessel density (67). Several findings indicate a role of maspin as an inhibitor of tumor cell invasion and metastasis formation. For example, a 15-mer oligopeptide mimicking the G-helix of maspin inhibited tumor cell invasion by binding to and and causing the internalilsation of integrin $\beta 1(68,69)$. Furthermore, it was shown that the RCL of maspin binds to a cell surface receptor that promotes cell adhesion to type I collagen and fibronectin and contributes to inhibition of tumor metastasis (70). Inhibition of migration of breast cancer cells by maspin is accomplished through inhibition of Ras related C3 botulinum substrate $1(\operatorname{Rac} 1)$ and cell division cycle 42 (cdc42) (71). The chromatin-binding property of maspin 


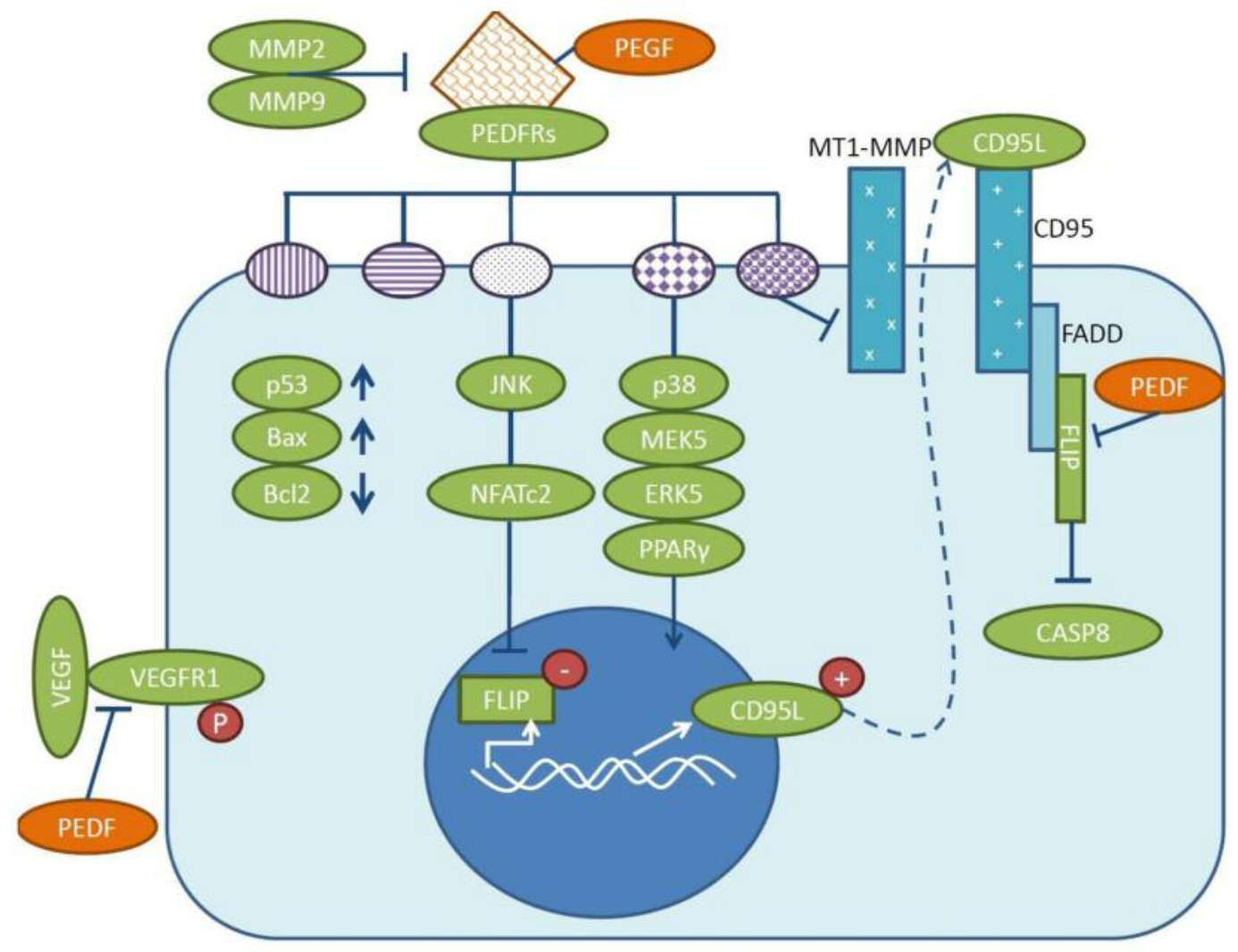

Figure 1. Anti-metastatic effects of pigment-epithelium derived factor (PEDF). PEDF can bind to several cell surface receptors and activate proapoptotic effectors such as CD95L, caspase 8, p53 and Bax. Activation of CD95L by PEDF has been shown in endothelial cells and tumor cells. In addition, PEDF inhibits VEGFR1 signaling in endothelial cells and anti-apoptotic protein Bcl2 in tumor cells. MMP2 and MMP9 inhibit PEDF and MT-MMP1 is inhibited by PEDF. Bax, Bcl2 associated X protein; CD95, cluster of differentiation 95; CD95L, CD95 ligand; ERK5, extracellular signal regulated kinase 5; FLIP, FLICE-inhibitory protein; MEK5, mitogen-activated protein kinase 5; MMP2, 9, matrix metalloproteinases 2 and 9; MT-MMP1, membrane-type matrix metalloproteinase 1; NFATc2, nuclear facor of activated T-cells c2; VEGF, vascular endothelial growth factor; VEGFR1, VEGF receptor 1.

affects cell-matrix interaction by promoting anti-migrational effects based on changes of the transcriptional programme of the corresponding cell $(65,66)$.

Target validation experiments in breast- and prostate cancerrelated preclinical systems for maspin as an anti-metastatic agent. In maspin-transfected MDA-MB 435 cells, reduced invasion in matrigel, decreased growth of xenograft tumors, and inhibition of metastasis formation in lymph nodes was noted (59). Recombinant maspin (r-maspin) inhibited matrigel invasion of MDA-MB-231 and MDA-MB-435 breast cancer and LNCaP, DU145 and PC3 prostate cancer cells. The latter functions were shown to be mediated by maspin acting at the cell surface (63). Similar effects were observed for murine $r-$ maspin in murine breast cancer cell lines CSMLO and CSML100 (72). The anti-metastatic function of maspin is also supported by experiments using transgenic mouse models
(73). Double transgenic mice were generated by crossing whey acidic protein (WAP)-SV40 large T and WAP-maspin mice. In these mice reduced growth of breast tumors and corresponding metastases was noted. Further in vivo experiments have corroborated the anti-metastatic function of maspin. Mammary fat pad implantation of syngeneic maspin overexpressing TM40D breast cancer cells revealed significant blockage of growth and metastasis formation (74). Another important finding was the demonstration of inhibition of osteolysis, tumor growth, angiogenesis and bone metastasis by maspin in a prostate cancer xenograft model (62). For this purpose, mock- or maspin-transduced DU-145 prostate cancer cells were transferred into fragments of human fetal bone and implanted into immuno-deficient mice (62). The underlying MOA seemed to be based on inhibition of uPA by maspin which also inhibited prostate cancer cell invasion in vitro (75). uPA converts plasminogen into plasmin which in turn can 


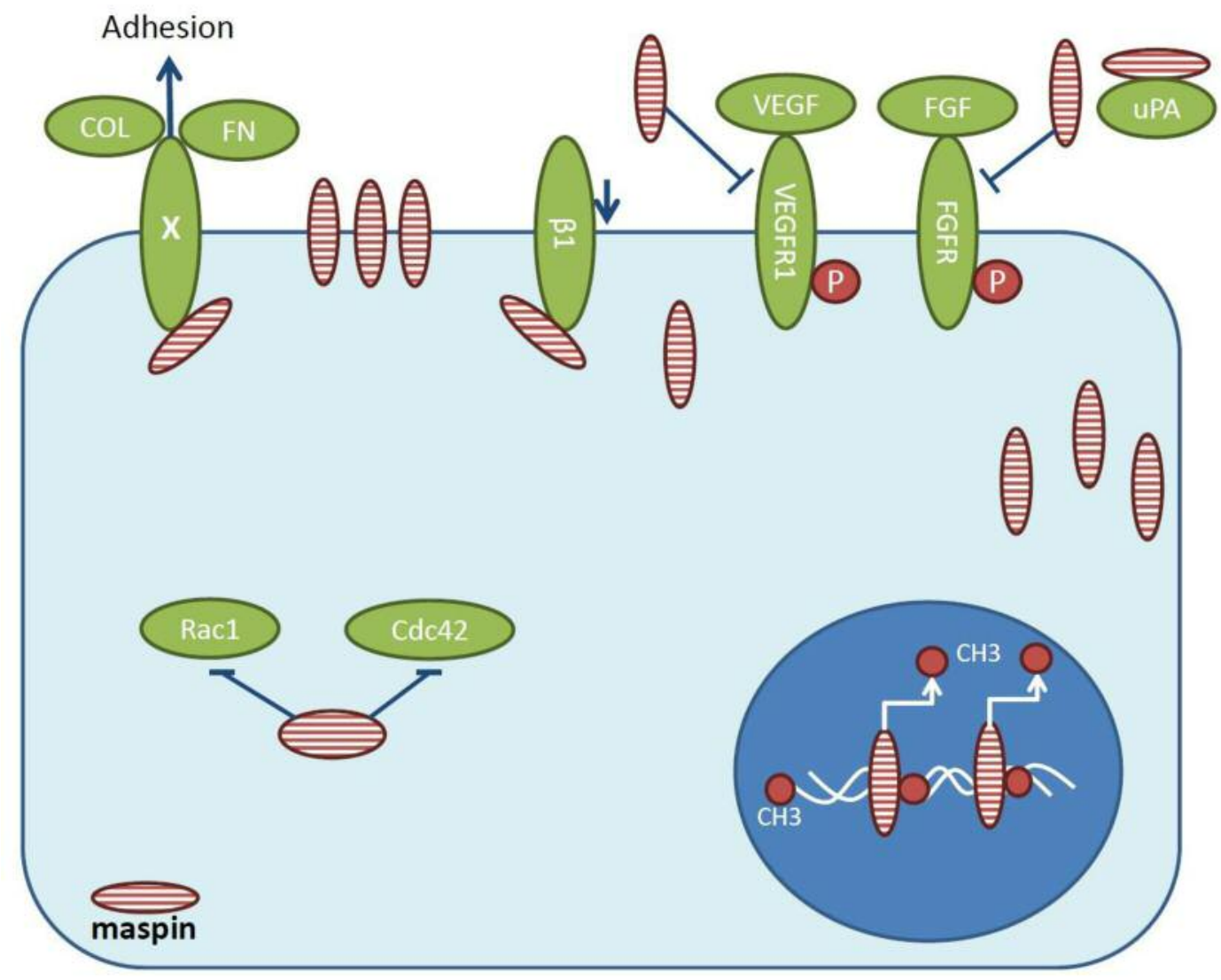

Figure 2. Anti-metastatic effects of maspin. Maspin can be secreted, localized in the cytoplasm and the nucleus and can associate with the plasma membrane. In endothelial cells, maspin inhibits VEGFR and FGFR signaling. In tumor cells maspin inhibits a not yet identified receptor X which promotes adhesion, promotes internalisation of migration-promoting integrin $\beta 1$, attenuates migration through inhibition of migration-promoting proteins Rac1 and cdc42 and can initiate an anti-invasive transcriptional program by chromatin modification (methylation) in the nucleus. Extracellularly, maspin can inhibit uPA. $\beta 1$, Integrin $\beta 1$; cdc42, cell division cycle 42; CH3, methyl; COL, collagen; FGF, fibroblast growth factor; FGFR1, FGF receptor 1; FN, fibronectin; Rac1, ras-related C3 botulinum substrate 1; uPA, urokinase-type plasminogen activator; VEGF, vascular endothelial growth factor; VEGFR1, VEGF receptor 1.

degrade components of the ECM and activate other zymogen proteases $(76,77)$. Yeast-derived recombinant maspin (78) inhibited the growth of established MDA-MB-435 xenograft tumors in a dose-dependent manner up to $25 \%$. Low-dose maspin plus paclitaxel resulted in $41 \%$ tumor growth inhibition which was superior to maspin or paclitaxel alone (79). The r-maspin was found in cytoplasmic vesicles through multiple endocytic mechanisms of uptake $(80,81)$. In addition to the general shortcomings of many therapeutic proteins, presently, systematic optimization of the anti-metastatic function of r-maspin is hampered by insufficient knowledge of the functional contribution of membrane- associated, cytoplasmic and nuclear maspin. Even if these issues can be solved, targeting of maspin to a cellular compartment necessary for its anti-metastatic function likely is another problem to be solved. Yet, another open issue is whether the anti-metastatic activity of maspin is dependent on is serpinrelated protease-inhibiting function. A study addressing this question found that maspin cannot undergo the stress-relaxed transition typical of proteinase-inhibitory serpins (61). On the other hand, the bone metastasis-inhibitory function of maspin was found to be linked to its proteinase-inhibitory activity. It is possible that these discrepancies are due to differences in the experimental conditions of the corresponding assay systems for assessment of its proteinase-inhibitory activity.

\section{Inter- $\alpha$ Trypsin Inhibitors}

Members of the inter- $\alpha$-trypsin Inhibitor (I $\alpha \mathrm{Is})$ family are composed of a common light (L)- chain and one or two of five heavy $(\mathrm{H})$-chains (82-86). The L-chain is also known as bikunin (Bk), and is a member of the Kunitz protease inhibitor 


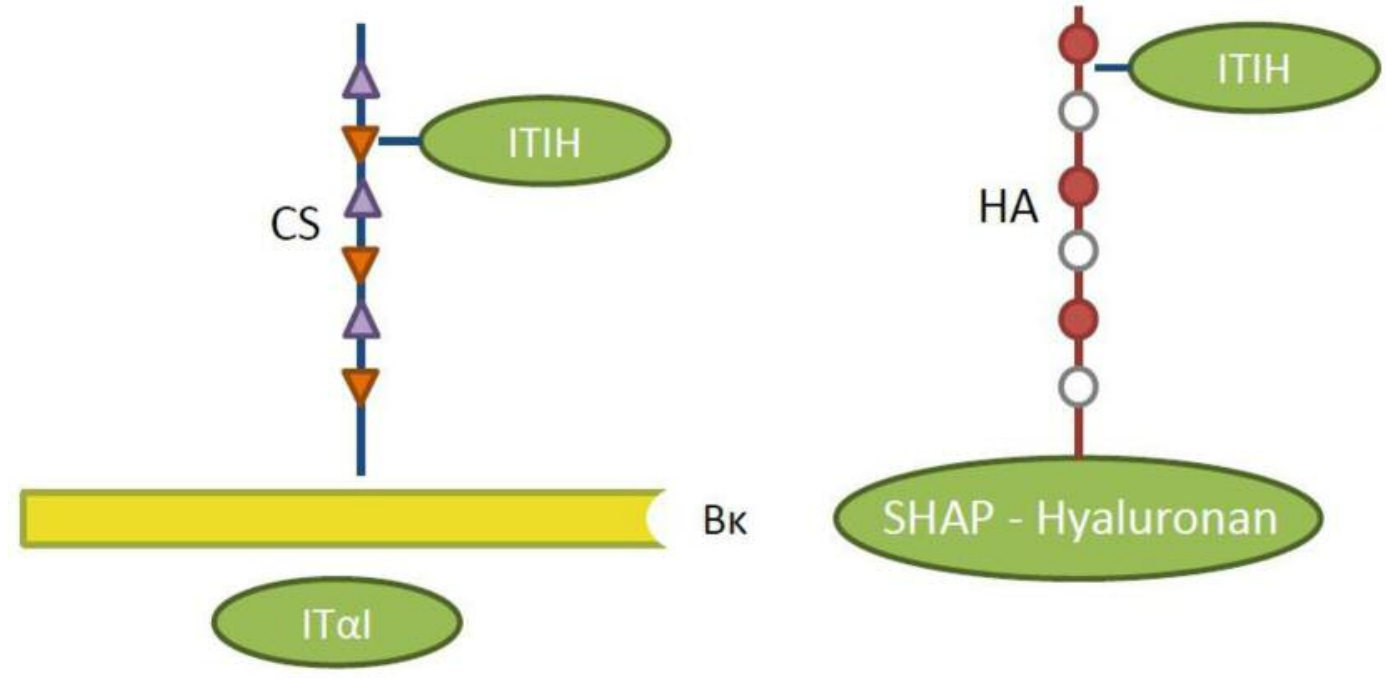

Figure 3. Composition of inter- $\alpha$-trypsin inhibitors and serum-derived hyaluronan-associated proteins. IT $\alpha 1$ is composed of a CS backbone ( $N$ acetylgalactosamine and glucuronic acid repeating disacharides), covalently linked to Bk and ITIH chains. SHAP is composed of HA (diglucuronic acid and $N$-acetyl-D-glucosamine repeating disacharides) covalently bound to ITIHs. CS, Chondroitin sulfate; HA, hyaluronic acid; ITaI, inter- $\alpha$ trypsin inhibitor; SHAP, serum-derived hyaluronan-associated proteins.

family. It is a chondroitin-based proteoglycan with a glycan component composed of $\mathrm{N}$-acetylgalactosamine and glucuronic acid as repeating disaccharides. The H-chains are composed of several modules such as vault and von Willebrand type A domains and have the capability to interact with the ECM. Linkage of the $\mathrm{H}$-chains and Bk occurs between the carboxyl group of the $\mathrm{C}$-terminal aspartic acid residue of the corresponding H-chain and the C-6 hydroxyl group of an internal $\mathrm{N}$-acetyl galactosamine residue of the chondroitin sulfate component of $\mathrm{Bk}$. I $\alpha$ I family proteins are mainly synthesized and secreted by the liver and are circulating in the blood at high concentrations between 0.15 and $0.5 \mathrm{mg} / \mathrm{ml}$ (84). The inter- $\alpha$ trypsin inhibitor heavy chains (ITIHs) can be covalently bound to locally produced hyaluronic acid (HA), a polymer of dissacharides composed of D-glucuronic acid and N-acetyl-D-glucosamine, via a transesterification reaction resulting in the formation of serumderived hyaluronan-associated proteins (SHAP) (84). Composition of IT $\alpha$ Is and SHAP are shown in Figure 3. ITIHs are involved in a variety of physiological functions such as fertilization, ovulation, inflammation and cancer (82-86).

Bikunin (Bk). Bk is present predominantly in amniotic fluid and urine of healthy individuals and inhibits a broad panel of proteases such as trypsin, chymotrypsin, cell surfacebound plasmin, leukocyte elastase and factor IXa (86). Bk exerts several invasion- and metastasis- inhibitory functions such as inhibition of expression of uPA at both levels of transcription and translation thus interfering with the conversion of plasminogen to plasmin at the cell surface
(87). Furthermore, Bk is able to inhibit the dimerization of CD44, resulting in the inhibition of the interaction of CD44 with HA and, consequently, CD44/HA-mediated activation of MAPK signaling (88). In addition to its antimetastatic function $\mathrm{Bk}$ has been shown to be involved in the inhibition of formation of urinary stones, inhibition of Ca-channels and as a modulator of inflammation $(86,89)$. Most of the bloodrelated Bk is covalently linked to ITIH chains. The MOA of $\mathrm{Bk}$ is summarized in Figure 4.

Inter- $\alpha$ trypsin inhibitor heavy chains (ITIHs). ITIHs are frequently down-regulated due to promotor methylation of the corresponding genes in diverse tumor entities (90). ITIH2 was found to be down-regulated in $70 \%$ of breast cancers $(n=50)$ and ITIH5 was strongly reduced in 42\% $(n=217)$ of invasive breast cancers in comparison to corresponding normal tissues $(91,92)$. In urothelial cancers (UC) $(n=55)$ loss of ITIH5 expression (61\% of cases) correlated with unfavourable prognosis of patients without distant metastases at first diagnosis (93). Most expression-related data are available for ITIH5. Analysis of 385 non-small cell lung carcinomas (NSCLC) found ITIH5 promoter methylation in $47 \%$ of samples and correlates with reduced mRNA expression (94). In particular, low ITIH5 mRNA expression was found in magnoid and squamoid NSCLC sub-types which are associated with an unfavorable prognosis (94). In acute myeloloid leukemia (AML), ITIH5 promoter hypermethylation was observed in 15 of 104 (14.4\%) of AML samples, however, there was no statistically significant correlation between the methylation status of the ITIH5 promoter and clinical 


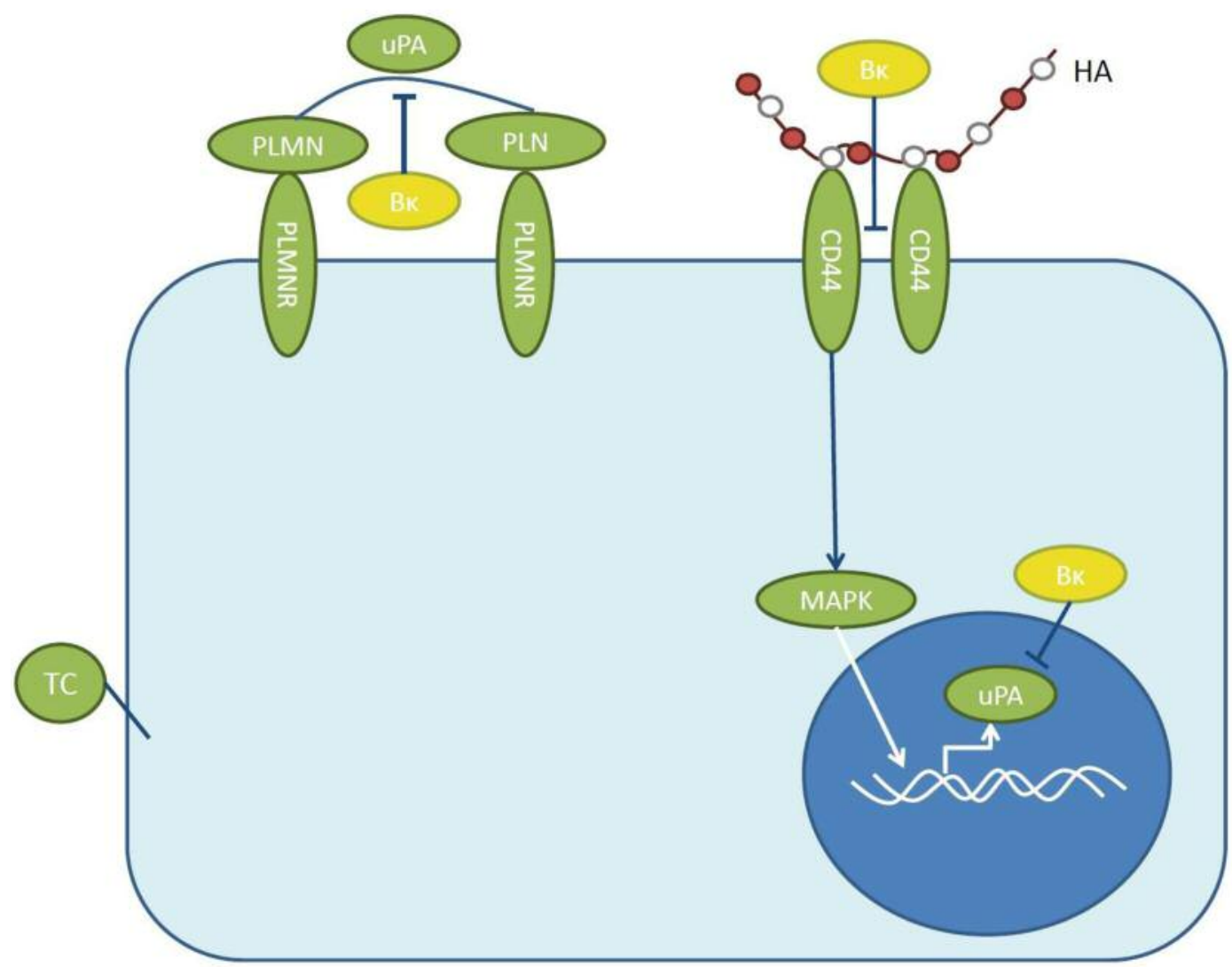

Figure 4. Anti-metastatic effects of Bikunin (Bk). Bk inhibits PLMNR mediated conversion of PLMN to PLN as well as dimerization of CD44, MAPK activation and transcriptional activation of Bk. Bk, Bikunin; CD44, cluster of differentiation 44; HA, hyaluronic acid; MAPK, mitogen-activated protein kinase; PLMN, plasminogen; PLMNR, plasminogen receptor; PLN, plasmin; uPA, urokinase plasminogen activator.

diagnostic parameters (95). In addition to these tumor-related findings, a role in inflammation and obesity has been identified for ITIH5 (96-98). ITIH5 is expressed in normal dermal fibroblasts, but not in epidermal keratinocytes and upregulated in inflammatory skin diseases such as psoriasis, atopic dermatitis and allergic contact dermatitis in the areas of immune reactions of the epidermis $(96,97)$. ITIH5 knock-out mice showed thinning of the epidermis and reduced capability of proliferation of dermal fibroblasts. These findings point to a role of ITIH5 in inflammatory disease and might be might be based on inhibition of degradation of the ECM. However, the functional contribution of ITIH5 in this context has to be investigated in more detail. Furthermore, a correlation between ITIH5 and obesity has been found (98). ITIH5 is expressed in adipocytes and adipose tissue and obese subjects display elevated ITIH5 levels in adipose tissue. Interestingly, ITIH5 mRNA expression was found to be reduced after diet-induced weight loss. These correlates might point to a possible function of ITIH5 as an adipokine regulating human metabolism. MOA of ITIHs are summarized in Figure 5. Analysis of steady-state
RNA levels (TCGA data) in several tumor entities and matching normal tissues revealed consistent down-regulation of ITIH5 mRNA in tumors of the bladder, breast cervix, colon, esophagus and thyroid carcinoma, lung adenocarcinoma, lung squamous carcinoma and tumors of rectum, stomach and the thyroid, whereas ITIH1-4 were only very rarely downregulated in tumor samples (Figure 6), emphasizing the important role of ITIH5 in cancer.

Metastasis-related target validation of Bk and ITIHs. In Bkdeficient knock-out mice a higher frequency of spontaneous lung metastases was observed 3-4 weeks after tumor inoculation in a 3LL Lewis lung cancer model (99). A single dose of i.p. injected Bk directly co-administered with tumor cell inoculation caused a significant reducion of number and mass of metastases in $\mathrm{Bk}^{-l-}$ mice. In addition, inhibition of MAPK signaling and inhibition of uPA and plasminogen activator inhibitor-1 (PAI-1) expression was observed in 3LL tumor cells (99). This is surprising because the terminal halflife time of $\mathrm{Bk}$ ranges between 4-30 min in humans, rats and 


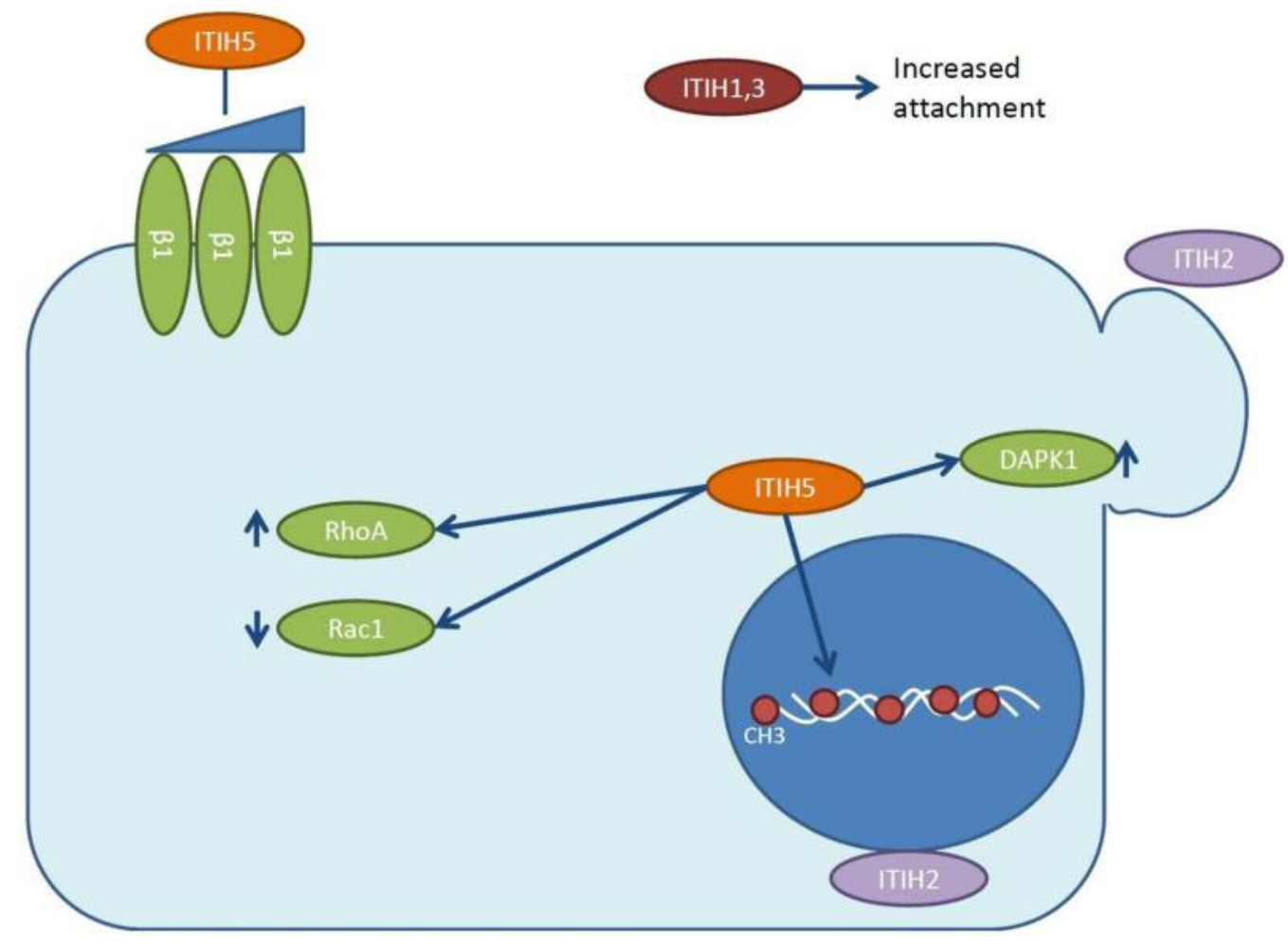

Figure 5. Anti-metastatic functions of inter-trypsin inhibitor heavy chains (ITIHs). All ITIHs are secreted by tumor cells; in addition, ITIH2 can be located at membrane ruffles and at the periplasmic membrane and ITIH5 can be found in endocytic vesicles in the cytoplasm. ITIH5 increases integrin $\beta 1$ expression, modulates activity of migration-related GTPases RhoA and Rac1 and epigenetically reprograms the transcriptional program of the tumor cell und supports transcription of tumor suppressor gene DAPK1. CH3, Methyl; DAPK1, death-associated kinase protein 1; ITIH, inter-trypsin inhibitor heavy chains; Rac1, ras-related C3 botulinum toxin substrate 1; Rho A, ras homologue A.

mice (100). Other studies have investigated the formation of macroscopic lung metastases derived from subcutaneous tumors implanted into the abdominal wall of $\mathrm{C} 57 \mathrm{Bl} / 6$ mice which were detectable 21 days after inoculation (101-103). Daily i.p. injection of Bk for 7 days and surgical removal of the primary tumors at day 7 after implantation, but not at day 14 , followed by Bk treatment as described, resulted in significant reduction of the number of lung metastases. However, the combination of $\mathrm{Bk}$ and etoposide led to inhibition of lung colonization also in surgery treated mice at day 14 after implantation $(101,102)$. In lung carcinoma cell line H460M, Bk decreased proliferation and inhibited growth of s.c. injected xenografts and the number of corresponding lung metastases after ectopic expression of Bk (103). Preliminary data for clinical evaluation of $\mathrm{Bk}$ in patients with advanced ovarian carcinoma were reported (89). Patients were first debulked surgically, followed by six cycles of chemotherapy, split in two arms, and treated with the above regimen with or without Bk on days 1 to 7 of each 21-day cycle. Five-year survival was improved from 29-44\% in the Bk-treated group as compared to the etoposide-only treated group ( $\mathrm{n}=28$ and 29 , respectively). However, there is no information available that this treatment was approved for the treatment of advanced ovarian carcinoma based on randomized studies with larger patient numbers.

For ITIH1 and ITIH3, metastasis-related target validation experiments were performed using green fluorescent proteinexpressing H460M cells which expressed ITIH1, 2 or 3 stably (103). ITIH1 and ITIH3 transfected cells showed increased attachment to matrigel in comparison to mock transfected control cells. Interestingly, tumor growth was not affected by expression of ITIH1,2 or 3. However, ITIH1 or 3 transfected cells possessed a reduced propensity to form lung metastases in a spontaneous metastasis model after s.c. injection (103). ITIH2 had no impact on metastasis formation in this model.

ITIH2 associated with Bk was isolated as a cell invasion inhibitory factor from C6 astrocytoma cells (104). In addition, U251 glioma cells stably transfected with ITIH2 which did not express H- or L-I $\alpha$ I related chains were used to show that ITIH2 inhibited invasion in three-dimensional collagen gels (104). Finally, ITIH2 was shown to localize to 


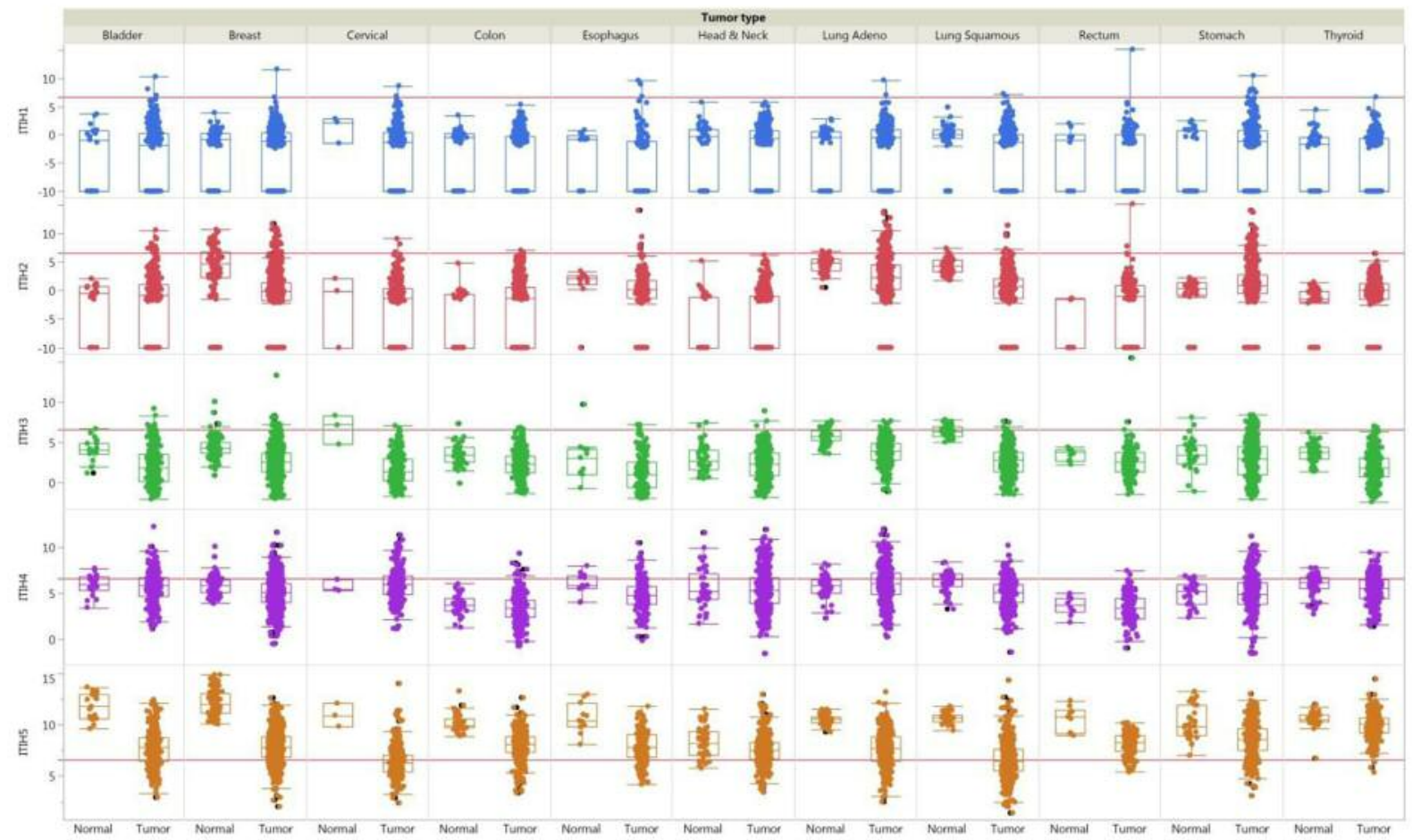

Figure 6. Expression of ITIH gene family members in tumor and matched normal samples by RNA sequencing of TCGA cohorts. Expression values (y-Axis) are provided as $\log 2$ normalized read counts. The red lines indicate a normalized read count of 100 separating very low from higher expression levels. Expression data are shown as box plots where the black line represent the data median, the black rectangle show the upper and lower $25 \%$ quartile (therefore, $50 \%$ of all data points are included in the black rectangle). All other data points, except for outliers lie within the upper and lower whiskers. Data are presented for the following tumor entities and matched normal tissues: bladder (408/19), breast (1100/112), cervical (306/3), colorectal (457/41), esophagus (185/11), head-and-neck: 522/44, lung adenocarcinoma (517/59), lung squamous cell carcinoma (501/51), rectum (167/10), stomach (415/359 and thyroid (509/59).

perinuclear regions, lamellipodia and membrane ruffles and to down-regulate AKT signaling in ITIH2-transfected C6cells. In these cells, ITIH2 inhibited proliferation without causing cell death and increased cell attachment to monolayers of U251 cells (104). Normally, ITIH2 is expressed in normal brain tissue and low-grade CNS tumors, but its expression is lost in high-grade CNS tumors including gliobastoma multiforme further underlining its potential role as an anti-invasive protein (104).

Similarly, ITIH5 transfected MDA-MB-231 breast cancer cells lost the ability to form lung metastases in a mouse model of experimental metastasis $(105,106)$. In these cells, migration and cell proliferation were impaired, expression of integrin receptors was shifted towards $\beta 1$ integrin receptor, Rac1 activity was decreased, and Rho activity was increased. The formation of epithelial-like cell clusters was observed in these transfectants, indicating changes in the dynamics of the ECM. Profound changes of the methylation status of histones was seen in the transfected cells, indicating that expression of ITIH5 might have induced epigenetic re-programming.
For example, tumor suppressor gene death-associated protein kinase 1 (DAPK1) was a gene upregulated by ITIH5, and its knock-down restored the impaired motility of the ITIH5transfected MDA-MB-231 cells. In addition, ITIH5 was identified as a suppressor of metastasis formation in pancreatic adenocarcinoma (107). An shRNA library was transfected into non-metastatic S2-028 pancreatic carcinoma cells which were subsequently injected into the spleens of mice. The characterisation of the resulting liver nodules revealed the presence of ITIH-5 specific shRNA suggesting the presence of the transfected cells. Conversely the expression of ITIH5 in metastatic pancreatic carcinoma cell lines inhibited motility and invasion while the reduction of ITIH5 expression using ITIH5 shRNA increased the number and mass of S2-028-derived liver metastases (107). Immunohistochemistry-based analysis of ITIH5 expression in pancreatic tumor samples demonstrated a positive correlation with survival and invasion/metastasis (107). It remains to be seen whether the observed phenomena can be recapitulated with recombinant ITIH5 or derivatives thereof. 
Target validation of ITIHs - critical issues. The terminal half-life of recombinant ITIHs may be short but probably can be improved by applying protein modification technologies (108). As outlined previously, high concentrations of ITIHs can be found in human serum and it remains to be proven that certain ITIHs are expressed at a reduced level in cancer patients as a prerequisite for substitution therapy with recombinant protein. The effect of defined recombinant ITIHs on inhibition of migration and proliferation in a panel of tumor cell lines with known ITIH status would be of interest to generate a strategy for ITIH-based anti-metastatic therapy. Finally, possible redundant as well as differentiating functions of I $\alpha$ I family members remain to be investigated.

\section{Therapeutic Aspects}

Most patients presenting in the clinic are diagnosed with disseminated tumor cells in blood or bone marrow $(109,110)$. An anti-metastatic agent, therefore, should possess both antiinvasive and anti-proliferative properties. Different scenarios of anti-metastatic intervention can be simulated preclinically in experimental and spontaneous metastasis models in the mouse (111-113). In these models, treatment can be varied e.g. with regard to time (early or late treatment) or regimen (single agent or combination therapy or treatment after adjunct therapy). In addition, many other variations of the treatment schedule are possible (111-113). In many types of tumors, diagnosis of metastases occurs after varying times of dormancy, a stage in which metastases are probably refractory to agents with anti-proliferative properties due to lack of proliferation $(111,112)$. Experiments investigating the intervention with drugs at this stage of metastasis are under development (114). Effective treatment of established metastases in preclinical models as well as in patients is impeded by several issues (111-113). Such obstacles are i) physical limitations of drug delivery due to poor tumor vacularization, ii) the blood-brain barrier for treatment of brain metastases, iii) the formation of chemo-preventive niches, iv) the acquisition of tumor stem cell-like characteristics, v) molecularly distinct properties between primary tumor and metastases and vi) heterogeneity of metastases (114-118). Thus, anti-metastatic agents targeting tumor cells, the 'seed' for metastases like e.g. with MMP inhibitors, medroxyprogesterone for re-activation of tumor suppressor $\mathrm{nm} 23$, cilengitide, a peptidic inhibitor of integrins $\alpha \mathrm{v} \beta 3$ and $\alpha v \beta 5$ or dasatinib, an inhibitor of src kinase, possessed basically no therapeutic efficacy (111). Alternatively, targeting the 'soil', i.e. the microenvironment of disseminated tumor cells is another strategy to treat metastatic disease. So, treatment with Denosumab, an antibody direct against receptor activator of NFkB ligand (RANK), which prevents osteoclastmediated degradation of bone gave rise to significant improvement of skeletal-related events in patients with bone metastasis (119). Other bone-metastasis targeting agents such as bisphosphonates and TGF $\beta$ inhibitors are under clinical development $(111,120,121)$.

We have described protein-related technical hurdles, target-related issues and clinical issues with an impact for further development of anti-metastatic proteins. The short half-life of the proteins as described such as PEDF, maspin and I IIs can be counteracted by improving the PK profile by protein modification(s) or through delivery technologies such continuous administration of the drug by implanted minipumps (122-126).

Comprehensive analysis of context-dependent functional data and incidence of target expression is a prerequisite for identification of tumor types potentially responding to target-specific anti-metastatic therapy. Another question is whether down-regulation of tumor- or serum levels of the corresponding anti-metastatic protein(s) correlates with the risk of metastasis formation in the tumor types as described above. Furthermore, comparative, functional in vitro and in vivo experiments using transfected tumor cells and/or recombinant therapeutic proteins might help to elucidate the modulation of anti-metastatic properties depending on the agent under consideration. Also, a differentiation between therapeutic proteins which affect metastases only and those which also have an impact on tumor cell proliferation is important for identifying the most promising combinations for therapy. For the clinical exploration of anti-metastatic proteins in adjuvant settings, patients with evidence of aggressive disease but no identifiyable distant metastases should be selected. Thus, metastasis-preventive trials (adjuvant trials) could be performed with smaller patient numbers and shorter duration times by selection of patients with multiple positive lymph nodes and/or known shortterm high incidence of relapse after standard treatment (127131). For disease recurrence, overall survival (OS) and progression free survival (PFS) could be chosen as appropriate endpoints. These types of suggested trials are markedly different from previous trials in which antimetastatic drugs were tested in patients with established metastases monitoring shrinkage of metastases (responses) in conjunction with OS and PFS $(111,127)$.

\section{References}

1 Mehlen P and Puisieux A: Metastasis: a question of life and death. Nat Rev Cancer 6: 449-458, 2006.

2 Valastyan S and Weinberg RA: Tumor metastasis: molecular insights and evolving paradigms. Cell 147: 275-292, 2011.

3 Vanharanta S and Massague J: Origins of metastatic traits. Cancer Cell 24: 410-421, 2013.

4 Steeg PS: Targeting metastasis. Nat Rev Cancer 16: 201-218, 2016.

5 Lambert AW, Pattabiraman DR and Weinberg RA: Emerging biological principles of metastasis. Cell 168: 670-691, 2017. 
6 Giancotti FG: Mechanisms governing metastatic dormancy and reactivation. Cell 155: 750-764, 2013.

7 Manjili MH: Tumor dormancy and relapse: from a natural byproduct of evolution to a disease state. Cancer Res 77: 25642569, 2017.

8 Kaplan RN, Rafii S and Lyden D: preparing the "soil": the premetastatic niche. Cancer Res 66: 11089-11093, 2006.

9 Peinado H, Zhang H, Matei IR, Costa-Silva B, Hoshino A, Rodrigues G, Psaila B, Kaplan RN, Bromberg JF, Kang Y, Bissell MJ, Cox TR, Giaccia AJ, Erler JT, Hiratsuka S, Ghajar $\mathrm{CM}$ and Lyden D: Pre-metastatic niches: organ-specific homes for metastases. Nat Rev Cancer 17: 302-317, 2017.

10 Nwabo Kamdje AH, Takam Kamga P, Tagne Simo R, Vecchio L, Seke Etet PF, Muller JM, Bassi G, Lukong E, Kumar Goel R, Mbo Amvene J and Krampera M: Developmental pathways associated with cancer metastasis: Notch, Wnt and hedgehog. Cancer Biol Med 14: 109-120, 2017.

11 Hosseini H, Obradovic MM, Hofmann M, Harper KL, Sosa MS, Werner-Klein M, Nanduro LK, Werno C, Ehrl C, Maneck M, patwary N, Haunschild G, Guzvic M, Reimelt C, Grauvogl M, Eichler N, Weber F, Hartkopf AD, Taran FA, Bruckner SY, Fehm T, Rack B, Buchholz S, Spang R, Meister G, AguirreGhiso JA and Klein CA: Early dissemination seeds metastasis in breast cancer. Nature 540: 552-558, 2016.

12 Klein CA: Selection and adaptation during metastatic cancer progression. Nature 501: 365-372, 2013.

13 Obenauf AC and Massague J: Surviving at a distance. Trends in Cancer 1: 76-91, 2015.

14 Heit C, Jackson BC, McAndrews M, Wright MW, Thompson DC, Dilverman GA, Nebert DW and Vasiliu V: Update of the human and mouse SERPIN gene superfamily. Hum Genomics 7: 22, 2013.

15 Potempa J, Korzus E and Travis J: The serpin superfamily of proteinase inhibitors: structure, function and regulation. J Biol Chem 269: 15957-15600, 1994.

16 Silverman GA, Bird PI, Carrell RW, Chruch FC, Coughlin RB, Gettins PG, Irving JA, Lomas DA, Luke CJ, Moyer RW, Pemberton PA, Remold-O’Donnell E, Salvesen GS, Travis J and Whisstock JC: The serpins are an expanding superfamily of structurally similar but functionally diverse proteins. Evolution, mechanism of inhibition, novel functions, and a revised nomenclature. J Biol Chem 276: 33293-33296, 2001.

17 Padron-Barthe L, Courta J, Lepretre C, Nagbou A and Torriglia A: Leukocyte elastase inhibitor, the precursor of L-DNAase II, inhibits apoptosis by interfering with caspase- 8 activation. Biochim Biophys Acta 1783: 1755-1766, 2008.

18 McGettrick AF, Barnes RC and Worrall DM: SCCA2 inhibits TNF-mediated apoptosis in transfected HeLa cells. The reactive centre loop sequence is essential for this function and TNFinduced cathepsin $\mathrm{G}$ is a candidate target. Eur J Biochem 268: 5868-5875, 2001.

19 Ashton-Rickardt PG: Serine protease inhibitors and cytotoxic T lymphocytes. Immunol Rev 235: 147-158, 2010.

20 Korpula-Mastalerz R and Dubin A: The intracellular serpin family. Acta Biochim Pol 43: 419-429, 1996.

21 Huntington JA: Serpin structure, function and dysfunction. J Thromb Haemost 9(Suppl 1): 26-34, 2011.

22 Pike RN, Bottomley SP, Irving JA, Bird PI, Whisstock JC: Serpins: Finely balanced conformational traps. IUBMB Life 54 : $1-7,2002$.
23 Kaslik G, Kardos J, Szabo E, Szilagyi L, Zavodszky P, Westler WM, Markley JL and Graf L: Effects of serpin binding on the target proteinase: global stabilization, localized increased structural flexibility, and conserved hydrogen bonding at the active site. Biochemistry 36: 5455-5564, 1997.

24 Valiente M, Obenauf AC, Jin X, Chen Q, Zhang XH, lee DJ, Chaft JE, Kris MG, Huse JT, Brogi E and Massague J: Serpins promote cancer cell survival and vascular co-option in brain metastasis. Cell 156: 1002-1006, 2014.

25 Myöhänen $\mathrm{H}$ and Vaheri A: Regulation and interactions in the activation of cell-associated plasminogen. Cell Mol Life Sci 61: 2840-2858, 2004.

26 Andreasen PA, Egelund R and Petersen HH: The plasminogen activation system in tumor growth, invasion and metastasis. Cell Mol Life Sci 57: 25-40, 2000.

27 Beer R, Franz G, Schöpf M, Reindl M, Zelger B, Schmutzhard E, Poewe W and Kampfl A: Expression of Fas and Fas ligand after experimental traumatic brain injury in the rat. $\mathrm{J}$ Cereb Blood Flow Metab 20: 669-677, 2000.

28 Wiencken-Barger AE, Mavity-Hudson J, Bartsch U, Schachner $\mathrm{M}$ and Casagrande VA: The role of L1 in axon pathfinding and fasciculation. Cereb Cortex 14: 121-131, 2004.

29 Weidle UH, Eggle D and Klostermann S: L1-CAM as a target for treatment of cancer with monoclonal antibodies. Anticancer Res 29: 4919-4931, 2009.

30 Lu X, Yang F, Fu DL and Jin C: L1 cell adhesion molecule as a therapeutic target in cancer. Expert Rev Anticancer Treat 16: 359-371, 2016.

31 Harbeck N, Thomssen C, Berger U, Ulm K, Kates RE, Höfler $\mathrm{H}$, Jänicke F, Graeff $\mathrm{H}$ and Schmitt M: Invasion marker PAI-1 remains a strong prognostic factor after long-term follow-up both for primary breast cancer and following first relapse. Breast Cancer Res Treat 54: 147-152, 1999.

32 Berger DH: Plasmin/plasminogen system in colorectal cancer. World J Surg 26: 767-771, 2002.

33 Foekens JA, Look MP, Peters HA, van Putten WL, Portengen $\mathrm{H}$ and Klin JG: Urokinase-type plasminogen activator and ist inhibitor PAI-1: predictors of poor response to tamoxifen therapy in recurrent breast cancer. J Natl Cancer Inst 87: 751$756,1995$.

34 Becerra SP and Notario V: The effects of PEDF on cancer biology: mechanisms of action and therapeutic potential. Nat Rev Cancer 13: 258-271, 2013.

35 Belkacemi L and Zhang SX: Anti-tumor effects of pigment epithelium-derived factor (PEDF): implications for cancer therapy. A mini-review. Exp Clin Cancer Res 35: 4, 2016.

36 Hoshina D, Abe R, Yamagishi SI and Shimizu H: The role of PEDF in tumor growth and metastases. Curr Mol Med 10: 292295, 2010.

37 Fernandez-Garcia NI, Volpert OV and Jiminiz B: Pigment epithelium-derived factor as a multifunctional antitumor factor. J Mol Med 85: 15-22, 2006.

38 Steele FR, Chader GJ, Johnson LV and Tombran-Tink J: Pigment epithelium-derived factor: neurotrophic activity and identification as a member of the serine protease inhibitor gene family. Proc Natl Acad Sci USA 90: 1526-1530, 1993.

39 Cheng G, Zhong M, Kawaguchi R, Kassai M, Al-Ubaidi M, Deng J, Ter-Stepanian M and Sun H: Identification of PLXDC1 and PLXDC2 as the transmembrane receptors for the multifunctional factor PEDF. Elife 3: e05401, 2014. 
40 Alcantara MB and Dass CR: Regulation of MT1-MMP and MMP-2 by the serpin PEDF: a promising new target for metastatic cancer. Cell Physiol Biochem 31: 487-494, 2013.

41 Tan ML, Choong PF and Dass CR: Anti-chondroma effects of PEDF mediated via molecules important to apoptosis, cell cycling, adhesion and invasion. Biochem Biophys Res Comm 398: 613-618, 2010.

42 Ladhani O, Sanchez-Martinez C, Orgaz JL, Jimenez B and Volpert OV: Pigment epithelium-derived factor blocks tumor extravasation by suppressing amoeboid morphology and mesenchymal proteolysis. Neoplasia 13: 633-642, 2011.

43 Halin S, Wikström P, Rudolfsson SH, Stattin P, Doll JA, Crawford SE and Bergh A: Decreased pigment epitheliumderived factor is associated with metastatic phenotype in human and rat prostate tumors. Cancer Res 64: 5664-5571, 2004.

44 Guan M, Yam HF, Su B, Chan KP, Pang CP, Liu WW, Zhang $\mathrm{WZ}$ and $\mathrm{Lu} \mathrm{Y}$ : Loss of pigment epithelium derived factor expression in glioma expression. J Clin Pathol 56: 277-282, 2003.

45 Uehara H, Miyamoto M, Kato K, Ebihara Y, Kaneko H, Hashimoto H, Murakami Y, Hase R, Takahashi R, Mega S, Shichinohe T, Kawarada Y, Itoh T, Oksushuba S, Kondo S and Katoh $\mathrm{H}$ : Expression of pigment epithelium-derived factor decreases liver metastasis and correlates with a favorable prognosis for patients with ductal pancreatic adenocarcinoma. Cancer Res 64: 3533-3537, 2004.

46 Ek ET, Dass CR, Contreras KG and Choong PF: Inhibition of orthotopic osteosarcoma growth and metastasis by multitargeted activities of pigment epithelium-derived factor. Clin Exp Metastasis 24: 93-106, 2007.

47 Abramson LP, Stellmach V, Doll JA, Cornwell M, Arensman RM and Crawford SE: Wilms'tumor growth is suppressed by antiangiogenic pigment epithelium-derived factor in a xenograft model. J Pediatric Surg 38: 336-342, 2003.

48 Orgaz JL, Ladhani O, Hoek KS, Fernandez-Barral A, Mihic D, Aguilera O, Seftor EA, Bernad A, Rodriguez-Peralto JL, Hendrix MJ, Volpert OV and Jiminenez B: Loss of pigment epithelium-derived factor enables migration, invasion and metastatic spread of human melanoma. Oncogene 28: 41474161, 2009.

49 Li L, Yao YC, Fang SH, Ma CQ, Cen Y, Xu ZM, Dai ZY, Li C, Li S, Zhang T, Hong HH, Qi WW, Zhou T, Li CY, Yang X and Gao GQ: Pigment epithelial-derived factor (PEDF)-triggered lung cancer cell apoptosis relies on p53 protein-driven Fas ligand (Fas-L) up-regulation and Fas protein cell surface translocation. J Biol Chem 289: 30785-30799, 2014.

50 Volpert OV, Zaichuk T, Zhou W, Reiher F, Ferguson TA, Stuart PM, Amin M and Bouck NP: Inducer-stimulated Fas targets activated endothelium for destruction by anti-angiogenic thrombospondin-1 and pigment epithelium-derived factor. Nat Med 8: 349-357, 2002.

51 Cai J, Chen Z, Ruan Q, Han S, Liu L, Qi X, Boyle SL, Hauswirth WW, Grant MB and Boulton ME: $\gamma$-secretase and presenilin mediate cleavage and phosphorylation of vascular endothelial growth factor receptor-1. J Biol Chem 286: 4251442523, 2011.

52 Biyashev D, Veliceasa D, Kwiatek, Sutanto MM, Cohen RN and Volpert OV: Natural angiogenesis inhibitor signals though Erk5 activation of peroxisome proliferator-activated receptor gamma (PPAR $\gamma$ ). J Biol Chem 285: 13517-13524, 2010.
53 Zaichuk TA, Shroff EH, Emmanuel R, Filleur S, Nelius T and Volpert OV: Nuclear factor of activated $\mathrm{T}$ cells balances angiogenesis activation and inhibition. J Exp Med 199: 15131522,2004

54 Manalo KB, Choong PF and Dass CR: Pigment epitheliumderived factor as an impending therapeutic agent against vascular epithelial growth factor-driven tumor-angiogenesis. Mol Carcinog 50: 67-72, 2011.

55 Fitzgerald DP, Subramanian P, Deshpande M, Graves C, Gordon I, Qian Y, Snitkovsky, Liewehr DJ, Steinberg SM, Paltan-Ortiz JD, Herman MM, Camphausen K, Palmieri D, Becerra SP and Steeg PS: Opposing effects of pigment epithelium-derived factor on breast cancer cell versus neuronal survival: implication for brain metastasis and metastasisinduced brain damage. Cancer Res 72: 144-153, 2012.

56 Yang $\mathrm{H}$ and Grossniklaus HE: Constitutive overexpression of pigment epithelium-derived factor inhibition of ocular melanoma growth and metastasis. Invest Ophthalmol Vis Sci 51: 28-34, 2010.

57 Ek ET, Dass CR, Contreras KG and Choong PF: Inhibition of osteosarcoma growth and metastasis by multitargeted antitumor activities of pigment epithelium-derived factor. Clin Exp Metastasis 24: 93-106, 2007.

58 Broadhead ML, Choong PF and Dass CR: Efficacy of continuously administered PEDF-derived synthetic peptides against osteosarcoma growth and metastasis. J Biomed Biotechnol 2012: 230298, 2012.

59 Zou Z, Anisowicz, Hendrix HJ, Thor A, Neveu M, Sheng S, Rafidi K, Seftor E and Sager R: maspin, a serpin with tumorsuppressing activity in human mammary epithelial cells. Science 263: 526-529, 1994.

60 Berardi R, Morgese F, Onofri A, mazzanti P, Pistelli M, Ballatore Z, Savini A, De Lisa M, Caramanti M, Rinaldi S, Pagliaretta S, Santoni M, Pierantoni C and Cascinu S: Role of maspin in cancer. Clin Transl Med 2: 8, 2013.

61 Pemberton PA, Wong DT, Gibson HL, Kiefer MC, Fitzpatrick PA, Sager R and Barr PJ: The tumor suppressor maspin does not undergo the stressed to relaxed transition or inhibit trypsin-like serine proteases. Evidence that maspin is not a protease inhibitory serpin. J Biol Chem 270: 15832-15837, 1995.

62 Cher ML, Biliran HR Jr, Bhagat S, Meng Y, Che M, Lockett J, Abrams J, Fridman R, Zachareas $M$ and Sheng S: Maspin expression inhibits osteolysis, tumor growth, and angiogenesis in a model of prostate cancer bone metastasis. Proc Natl Acad Sci USA 100: 7847-7852, 2003.

63 Chen EI and Yates YR: Maspin and tumor metastasis. IUMB Life 58: 25-29, 2006.

64 Khalkhali-Ellis Z: Maspin: the new frontier. Clin Cancer Res 12: 7279-7283, 2006.

65 Goulet B, Kennette W, Ablack A, Postenka CO, Hague MN, Mymryk JS, Tuck AB, Giquere V, Chambers AF and Lewis JD: Nuclear localization of maspin is essential for its inhibition of tumor growth and metastasis. Lab Invest 91: 1181-1187, 2011.

66 Goulet B, Chan G, Chambers AF and Lewis JD: An emerging role for the nuclear localization of maspin in the suppression of tumor progression and metastasis. Biochim Cell Biol 90: 22$38,2012$.

67 Zhang M, Volpert O, Shi YH and Bouck N: Maspin is an angiogenesis inhibitor. Nat Med 6: 196-199, 2000. 
68 Cella N, Contreras A, Latha K, Rosen JM and Zhang M: Maspin is physically associated with $\beta 1$ integrin regulating cell adhesion in mammary epithelial cells. FASEB J 20: 1510-1512, 2006.

69 Ravenhill L, Wagstaff L, Edwards DR, Ellis V and Bass R: Ghelix of maspin mediates effects on cell migration and adhesion. J Biol Chem 285: 36285-36292, 2010.

70 Seftor RE, Seftor EA, Sheng S, Pemberton PA, Sager R and Hendrix MJ: Maspin suppresses the invasive phenotype of human breast carcinoma. Cancer Res 58: 5681-5685, 1998.

71 Shi HY, Stafford LJ, Liu Z and Zhang M: Maspin controls mammary tumor cell migration through inhibiting Rac1 and CDc42, but not the RhoA GTPase. Cell Motil Cytoskeleton 64: 338-346, 2007.

72 Zhang M, Sheng S, Maass N and Sager R: mMaspin: the mouse homolog of a human tumor suppressor gene inhibits mammary tumor invasion and motility. Mol Med 3: 49-59, 1997.

73 Shi HY, Zhang W, Liang R, Kittrell F, templeton NS, Medina $\mathrm{D}$ and Zhang M: Modeling human breast cancer metastasis in mice: maspin as a paradigm. Histol Histopathol 18: 201-206, 2003.

74 Shi HY, Zhang W, Liang R, Abraham S, Kittrell FS, Medina D and Zhang M: Blocking tumor growth, invasion, and metastases by maspin in a syngeneic breast cancer model. Cancer Res 61 : 6945-6951, 2001.

75 Biliran H Jr and Sheng S: Pleiotrophic inhibition of pericellular urokinase-type plasminogen activator system by endogenous tumor suppressive maspin. Cancer Res 61: 8676-8682, 2001.

76 Winding B, NicAmhlaobh R, Misander A, Hoegh-Andersen P, Andersen TL, Holst-Hasen C, Heegard AM, Foged NT, Brünner $\mathrm{N}$ and Delaisse JM: Synthetic matrix metalloproteinse inhibitors inhibit growth of established breast cancer osteolytic lesions and prolong survival in mice. Clin Cancer Res 8: 1932-1939, 2002.

77 Del Rosso M, Fibbi G, Pucci M, D’Alessio, Del Rosso A, Magnelli L and Chiarugi V: Multiple pathways of cell invasion are regulated by multiple families of serine proteases. Clin Exp Metastasis 19: 193-207, 2002.

78 Sheng S, Pemberton PA and Sager R: Production, purification and characterization of recombinant maspin proteins. J Biol Chem 269: 30988-30993, 1994.

79 Bodenstine TM, Seftor RE, Kalkhali-Ellis Z, Seftor EA, Pemberton PA and Hendrix MJ: Maspin: molecular mechanisms and therapeutic implications. Cancer Metastasis Rev 31: 529$551,2012$.

80 Bodenstine TM, Seftor RE, Seftor EA, Khalkhali-Ellis Z, Samii NA, Monarrez JC, Chandler GS, Pemberton PA and Hendrix MJ: Internalisation by multiple endocytic pathways and lysosomal processing impact maspin-based therapeutics. Mol Cancer Res 12: 1480-1491, 2014.

81 Pemberton PA, Tipton AR, Pavloff N, Smith J, Erickson JR, Mouchabeck ZM and Kiefer MC: Maspin is an intracellular serpin that partitions into secretory vesicles and is present at the cell surface. J Histochem Cytochem 45: 1697-16706, 1997.

82 Salier JP, Rouet P, Raguenez G and Daveau M: The inter-alphainhibitor family: from structure to regulation. Biochem J 315: 1-9, 1996.

83 Zhou L, Hascall VC and Kimata K: Inter-alpha-trypsin inhibitor, a covalent protein-glycosaminoglycan-protein complex. J Biol Chem 279: 38079-38082, 2004.
84 Bost F, Diarra-Mehrpour M and Martin JP: Inter-alpha-trypsin inhibitor proteoglycan family - a group of proteins binding and stabilizing the extracellular matrix. Eur J Biochem 252: 339346, 1998

85 Zhuo L and Kimata K: Structure and function of inter-alphatrypsin inhibitor heavy chains. Connect Tissue Res 49: 311-320, 2008.

86 Fries E and Blom AM: Bikunin - not just a plasma proteinase inhibitor. Int J Biochem Cell Biol 32: 125-137, 2000.

87 Kobayashi H, Suzuki M, Sun GW, Hirashima Y and Terao T: Suppression of urokinase-type plasminogen activator expression from human ovarian cancer cells by urinary trypsin inhibitor. Biochim Biophys Acta 1481: 310-316, 2000.

88 Kobayashi H, Suzuki M, Tanaka Y, Hirashima Y and Terao T: Suppression of urokinase expression and invasiveness by urinary trypsin inhibitor is mediated through inhibition of protein kinase C- and MEK/ERK/c-Jun-dependent signaling pathways. J Biol Chem 276: 2015-2022, 2001.

89 Kobayashi H, Suzuki M, Hirashima Y and Terao: The protease inhibitor bikunin, a novel anti-metastatic agent. Biol Chem 384: 749-754, 2003.

90 Hamm A, Veeck J, Bektas N, Wild PJ, Hartmann A, Hendrichs U, Kristiansen G, Werbowetski-Ogilvie T, Del Maestro R, Knüchel R and Dahl E: Frequent expression loss of Inter- $\alpha$ trysin inhibitor heavy chain (ITIH) genes in multiple human solid tumors: a systematic expression analysis. BMC Cancer 8 : 25, 2008

91 Veeck J, Chorovicer N, Naami A, Breuer E, Zafrakas M, Bektas N, Dürst M, Kristiansen G, Wild PJ, Hartmann A, Knuechel R and Dahl E: The extracellular matrix protein ITIH5 is a novel prognostic marker in invasive node-negative breast cancer and its aberrant expression is caused by promoter hypermethylation. Oncogene 27: 865-876, 2007.

92 Himmelfarb M, Klopock E, Grube S, Staub E, Klaman I, Hinzmann B, Kristiansen G, Rosenthal A, Dürst M and Dahl E: ITIH5, a novel member oft he inter-alpha-trypsin hinhibitor heavy chain family is downregulated in breast cancer. Cancer Lett 204: 69-77, 2004

93 Rose M, Gaisa NT, Antony P, Fiedler D, Heidenreich A, Otto W, Denzinger S, Bertz S, Hartmann A, Karl A, Knüchel R and Dahl E: Epigenetic inactivation of ITIH5 promotes bladder cancer progressin and predicts early relapse of pT1 high-grade urothelial tumors. Carcinogenesis 35: 727-736, 2014.

94 Dötsch MM, Kloten V, Schlensog M, Heide T, Braunschweig T, Veeck J, Petersen I, Knüchel R and Dahl E: Low expression of ITIH5 in adenocarcinoma of the lung is associated with unfavorable patients'outcome. Epigenetics 10: 903-912, 2015.

95 Oing C, Jost E, Dahl E, Wilop S, Brümmendorf TH and Galm O: Aberrant DNA hypermethylation of the ITIH5 tumor suppressor gene in acute myeloid leukemia. Clin Epigenetics 2: 419-423, 2011.

96 Hennies HC: All is balanced: inter- $\alpha$-trypsin inhibitors as unseen extracellular matrix proteins in epidermal morphology and differentiation. Exp Dermatol 24: 661-662, 2015.

97 Huth S, Heise R, Vetter-Kauczok CD, Skazik C, Marquardt Y, Czaja K, Knüchel R, Merk HF, Dahl E and Baron JM: Inter- $\alpha$ trypsin heavy chain 5 (ITIH5) is overexpressed in inflammatory skin diseases and affects epidermal morphology in constitutive knockout mice and murine 3D skin models. Exp Dermatol 24: 663-668, 2015. 
98 Anveden A, Siöholm K, Jacobsen P, Palsdottir V, Froquel P, AlDaghri N, McTernan PG, Meihert N, Arner P, Sjöström L, Carlsson LM and Svensson PA: ITIH-5 expression in human adipose tissue is increased in obesity. Obesity 20: 708-714, 2012.

99 Yagyu T, Kobayashi H, Matsuzaki H, Wakahara K, Kondo T, Kurita N, Sekino $\mathrm{H}$ and Inagaki K: Enhanced spontaneous metastasis in bikunin-deficient mice. Int J Cancer 118: 23222328, 2006.

100 Jönsson-Berling BM and Ohlsson K: Distribution and elimination of intravenously injected urinary trypsin inhibitor. Scand J Clin Lab Invest 51: 549-557, 1991.

101 Kobayashi H, Shinohara H, Fujie M, Gotoh J, Itoh M, Takeuchi $\mathrm{K}$ and Terao $\mathrm{T}$ : Inhibition of metastasis of Lewis lung carcinoma by urinary trypsin inhibitor in experimental and spontaneous metastasis models. Int. J. Cancer 63: 455-462, 1995.

102 Kobayashi H, Shinohara H, Gotoh J, Fujie M, Fujishiro S and Terao T: Anti-metastatic therapy by urinary trypsin inhibitor in combination with an anti-cancer agent. Br J Cancer 72: 11311137, 1995.

103 Paris S, Sesboüe R, Delpech B, Chauzy C, Thiberville L, Martin JP, Frebourg T and Diarra-Mehrpour M: Inhibition of tumor growth and metastatic spreading by overexpression of inter-alpha-trypsin family chains. Int J Cancer 97: 615-620, 2002.

104 Werbowetski-Ogikivie TE, Agar NY, Waldkircher de Olivera RM, Faury D, Antel JP, Jabado N and Del Maestro RF: Isolation of natural inhibitor of human malignant glial cell invasion: inter alpha-trypsin inhibitor heavy chain 2. Cancer Res 66: 1464-1472, 2006.

105 Rose M, Kloten V, Noetzel E, Gola L, Ehling J, Heide T, Meurer SK, Gaiko-Shcherbak A, Sechi AS, Huth S, Weiskirchen R, Klaas O, Antonooulos W, Lin Q, Wagner W, Veeck J, Gremse F, Steitz J, Knüchel R and Dahl E: ITIH5 mediates epigenetic reprogramming of breast cancer cells. Mol Cancer 16: 44, 2017.

106 Steinbuch M: The inter-alpha-trypsin inhibitor. Methods Enzymol 45: 760-772, 1976.

107 Sasaki K, Kurahara H, Young ED, Natsugoe S, Ijichi A, Iwakuma $\mathrm{T}$ and Welch DR: Genome-wide in vivo RNAi screen identifies ITIH5 as a metastasis suppressor in pancreatic cancer. Clin Exp Metastasis 34: 229-239, 2017.

108 Werle $\mathrm{M}$ and Bernkop-Schnürch A: Strategies to improve plasma half life time of peptide and protein drugs. Amino Acids 30: 351-367, 2006.

109 Pantel K, Alix-Panabieres C and Riethdorf S: Cancer micrometastases. Nat Rev Clin Oncol 6: 339-351, 2009.

110 Alix-Panabieres C and Pantel K: Circulating tumor cells: liquid biopsy of cancer. Clin Chem 59: 110-118, 2013.

111 Steeg PS: Targeting metastasis. Nat Rev Cancer 16: 201-218, 2016.

112 Valastyan S and Weinberg RA: Tumor metastasis: molecular insights and evolving paradigms. Cell 147: 275-292, 2011.

113 Lambert AW, Pattabiraman DR and Weinberg RA: Emerging principles of metastasis. Cell 168: 670-691, 2017.
114 Lin WC, Raibhandari N and Wagner KU: Cancer cell dormancy in novel mouse models for reversible pancreatic cancer: a lingering challenge in the development of targeted therapies. Cancer Res 74: 2138-2143, 2014.

115 Qian CN, Mei Y and Zhang J: Cancer metastases: issues and challenges. Chin J Cancer 36: 38, 2017.

116 Aglianao A, Calvo A and Box C: The challenge of targeting cancer stem cells to halt metastasis. Sem Cancer Biol 44: 2542, 2017.

117 Bohn JP, Pall G, Stockhammer G and Steurer M: Targeted therapies for the treatment of brain metastases in solid tumors. Target Oncol 11: 263-275, 2016.

118 Turajlic S and Swanton C: Metastasis as an evolutionary process. Science 352: 169-175, 2016.

119 Macedo F, Ladeira K, Pinho F, Saraiva N, Bonito N, Pinto L and Goncalves F: Bone Metastasis: An overview. Oncol Rev 11: 321, 2017.

120 Casimiro S, Ferreira AR, Mansinho A, Alho I and Costa L: Molecular mechanisms of bone metastasis: which targets came from the bench to the bedside? Int J Mol Sci 17: e1415, 2016.

121 Juarez P and Guise TA: Tgf-Beta pathway as a therapeutic target in bone metastases. Curr Pharm Des 16: 1301-1312, 2010.

122 Jenkins N: Modifications of therapeutic proteins: challenges and prospects. Cytotechnology 53: 121-125, 2007.

123 Leader B, Baca QJ and Golan DE: Protein therapeutics: a summary and pharmacological classification. Nat Rev Drug Discov 7: 21-39, 2008.

124 Pisal DS, Kosloski MP and Balu-Iyer SV: Delivery of therapeutic proteins. J Pharm Sci 99: 2557-2575, 2010.

125 Strohl WR: Fusion proteins for half-life extension of biologics as a strategy to make biobetters. BioDrugs 29: 215-239, 2015.

126 Lagasse HA, Alexaki A, Simhadri VL, Katagiri NH, Jankowski, Sauna ZE and Kimchi-Safaty C: Recent advances in (therapeutic protein) drug development. F100Res 6: 113, 2017.

127 Steeg PS and Theodorescu D: Metastasis: a therapeutic target in cancer. Nat Clin Pract Oncol 5: 206-219, 2008.

128 Fischer R, Breidert M, Keck T, Makowiec F, Lohrmann C and Harder J: Early recurrence of pancreatic cancer after resection and during adjuvant chemotherapy. Saudi J Gastroenterol 18: 118-121, 2012.

129 Steeg PS: Perspective: the right trials. Nature 485: S58-59, 2012.

130 Asai N, Ohkuni Y, Kaneko N, Yamaguchi E and Kubo A: Relapsed small cell lung cancer: treatment options and latest developments. Ther Adv Med Oncol 6: 69-82, 2014.

131 Wong MS, Sidik SM, Mahmud R and Stanslas J: Molecular targets in the discovery and development of novel antimetastatic agents: current progress and future prospects. Clin Exp Pharmacol Physiol 40: 307-319, 2013.

Received April 19, 2018

Revised June 4, 2018

Accepted June 5, 2018 